\title{
Enhancement of Chrysotile Carbonation in Alkali Solution
}

\author{
Kyoung Won Ryu ${ }^{1}$, Young Nam Jang ${ }^{1, *}$ and Myung Gyu Lee ${ }^{2}$ \\ ${ }^{1}$ Geologic Environment Division, Korea Institute of Geoscience and Mineral Resources (KIGAM), \\ Gwahang-no 92, Yuseong-gu, Daejeon 305-350, Korea \\ ${ }^{2}$ Resources Recycling Engineering Department, University of Science and Technology of Korea, \\ Gwahang-no 113, Yuseong-gu, Daejeon 305-333, Korea
}

The carbonation of chrysotile $\left[\mathrm{Mg}_{3} \mathrm{Si}_{2} \mathrm{O}_{5}(\mathrm{OH})_{4}\right]$ was studied at various temperatures in order to examine the carbonation rate and $\mathrm{Mg}$ leaching properties in an alkali solution and distilled water using the direct method. For the efficient carbonation reaction, the chrysotile was converted to metachrysotile by heating at $630^{\circ} \mathrm{C}$ for $2 \mathrm{~h}$. The carbonation rate was found to increase with the reaction temperature: 5 and $31 \%$ at $100^{\circ} \mathrm{C}$ and 45 and $53 \%$ at $260^{\circ} \mathrm{C}$ in distilled water and alkali solution, respectively. The carbonation in the alkali solution was faster producing well-faceted rhombohedral magnesite $\left(\mathrm{MgCO}_{3}\right)$ in comparision to the case in the distilled water. Highly crystalline magnesite could be obtained after the carbonation for $1 \mathrm{~h}$ at $260^{\circ} \mathrm{C}$ under a $\mathrm{CO}_{2}$ pressure of $3 \mathrm{MPa}$ in the alkali solution.

The additional object of this study was to convert the fibrous chrysotile to a non-hazardous material. During carbonation, the magnesite exhibited the typical rhombohedral morphology while the unreacted chrysotile changed primarily to aggregations of chrysotile crystals. This result has an important implication for the elimination of toxicity through the transformation of chrysotile asbestos into a non-hazardous material. [doi:10.2320/matertrans.M2012059]

(Received February 17, 2012; Accepted April 13, 2012; Published May 30, 2012)

Keywords: chrysotile, carbon dioxide, carbonation, magnesite, asbestos

\section{Introduction}

Chrysotile is one of the serpentine group and its crystal structure is characterized by the spiraling of both the silicate $\left(\mathrm{SiO}_{4}\right)^{2-}$ tetrahedral sheet as an inner layer and the magnesium hydroxide $\left[\mathrm{Mg}-(\mathrm{OH})_{2}\right]$ as an outer layer. ${ }^{1)}$ Thus, the fibers can also be represented by a tubular scroll-like morphology.

Owing to their outstanding technological properties, such as fire protection, moisture control, and thermal insulation, asbestos minerals have been extensively used since the beginning of the last century for innumerable industrial applications. Most of these applications involve products that contain chrysotile asbestos, which accounted for over $90 \%$ of worldwide asbestos production. ${ }^{2)}$

However, on account of its asbestiform morphology, chrysotile is considered to be a carcinogenic health hazard. Consequently, asbestos must be removed and properly managed in accordance with the safety regulations. The most common method of dealing with hazardous asbestos is disposing of it in a suitable landfill, but the disposal of this kind without pretreatment is forbidden. However, their pre-treatment involves many disadvantages, including high cost, long intervention times, large production of toxic waste, and risk of environmental pollution during and after the operation. ${ }^{3)}$ Most of the chemical processes involve the covering of the surface of the asbestos fiber with organic or inorganic substances; in addition, strong acids can be used to destroy the fiber structure. Unfortunately, such acids are considered to be even more hazardous than chrysotile asbestos itself., ${ }^{4)}$ ) Other popular natural treatments that convert chrysotile asbestos into non-hazardous substances are the thermal conversion ${ }^{6)}$ and physical conversion using microwave radiation and mechanical methods. ${ }^{7-10)}$

The increasing atmospheric concentration of $\mathrm{CO}_{2}$, attributed to fossil fuel combustion, is a serious problem that leads to the global warming. A variety of options for reducing

*Corresponding author, E-mail: crystal@kigam.re.kr
$\mathrm{CO}_{2}$ emissions have been extensively studied; among them, mineral carbonation has recently attracted much interest because of its ability to sequester $\mathrm{CO}_{2}$ indefinitely as chemically stable carbonates through a spontaneous exothermic reaction. ${ }^{11-13)}$ Serpentine is an attractive mineral reactant for mineral sequestration on account of its reserves and its relatively high magnesium content. The reserves of serpentine are much greater than any other $\mathrm{Ca}, \mathrm{Mg}$ minerals.

Most of the carbonation of chrysotile was carried out in neutral or acidic $\mathrm{pH}$ because this is advantageous for the mineral extraction reaction to occur. It is well known that acids destroy the fiber structure of chrysotile asbestos. In contrast, the carbonation reaction should be carried out under the appropriately basic $\mathrm{pH}$ conditions requiring the $\mathrm{pH}$ swing reaction. Nevertheless, to the best knowledge of the authors, the dissolution and carbonation of chrysotile through the direct method in an alkali solution have never been attempted.

The aims of this study were to investigate the direct mineral carbonation in terms of the carbonation rate, $\mathrm{Mg}$ leaching properties, and the conversion of fibrous chrysotile to a non-hazardous material under economically viable and safe conditions through a comparative study using an alkali solution and distilled water.

\section{Experiments}

\subsection{Materials}

The chrysotile asbestos fibers used in this study were obtained from ChungYang, Korea. XRD data indicated that the starting material was pure chrysotile (Fig. 1(a)). The chemical composition of the chrysotile was $39.4 \mathrm{SiO}_{2}$ and 38.8 mass \% $\mathrm{MgO}$ (Table 1). The ignition crystalline water content was estimated to be 13 mass \%. Most chrysotile is crystallized as bundles or has a cylindrical structure for the fibrils, which are $20-50 \mathrm{~nm}$ in diameter (Figs. 2(a), 3(a)). Chrysotile exhibits complete order with respect to [100], but it exhibits no order with respect to [010]. ${ }^{14)}$ 


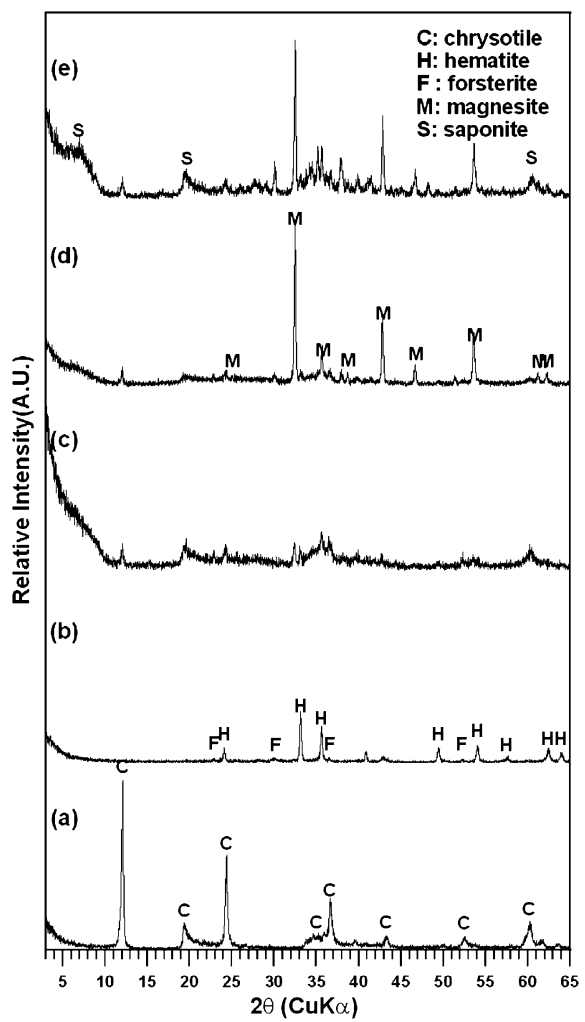

Fig. 1 XRD patterns of raw material (a), activated chrysotile (b), and carbonation products after at $80^{\circ} \mathrm{C}(\mathrm{c})$, at $140^{\circ} \mathrm{C}(\mathrm{d})$, at $260^{\circ} \mathrm{C}$ (e).

Table 1 Chemical composition of the starting material (mass\%).

Component $\mathrm{SiO}_{2} \quad \mathrm{MgO} \mathrm{CaO} \mathrm{Al}_{2} \mathrm{O}_{3} \quad \mathrm{Na}_{2} \mathrm{O} \quad \mathrm{K}_{2} \mathrm{O} \quad \mathrm{Fe}_{2} \mathrm{O}_{3} \quad \mathrm{MnO} \mathrm{TiO}_{2}$ Total

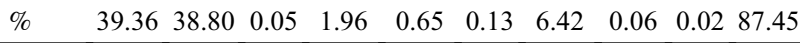

(a)

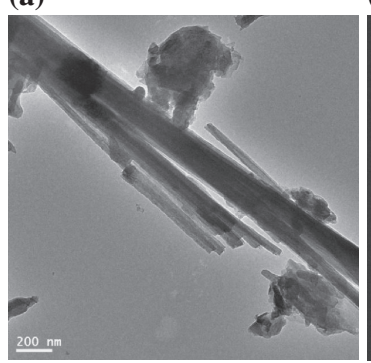

(b)

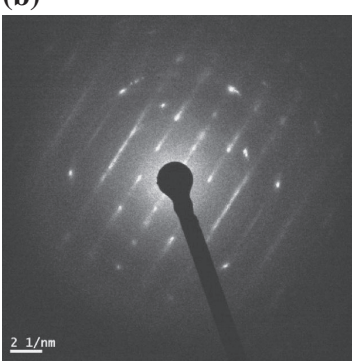

Fig. 2 TEM image of heated chrysotile. A fibrous heated chrysotile with a tubular morphology for each fibril (a) and the electron diffraction pattern (b).

At 600 to $650^{\circ} \mathrm{C}$, chrysotile undergoes dehydration

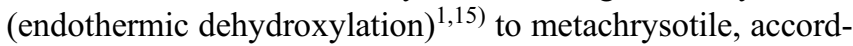
ing to the following reaction:

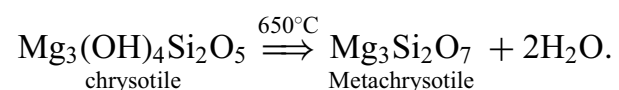

As heating chrysotile is expected to facilitate its formation of carbonate, the chrysotile was heated at $630^{\circ} \mathrm{C}$ for $2 \mathrm{~h}$ in atmosphere. The formation of metachrysotile as amorphous phase was confirmed by XRD analysis: ${ }^{15)}$ the chrysotile peaks disappeared completely and forsterite and hematite peaks were observed (Fig. 1(b)). The TEM image of heated chrysotile also revealed its typical morphology and structure (Fig. 2).

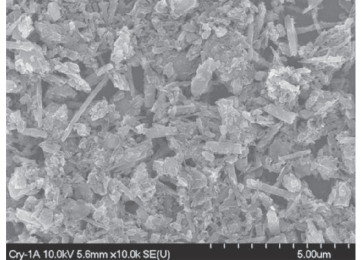

(a)

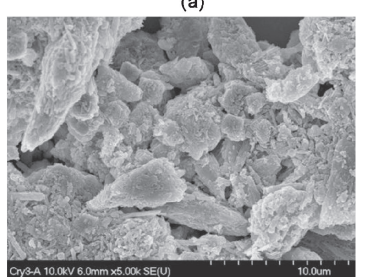

(b)

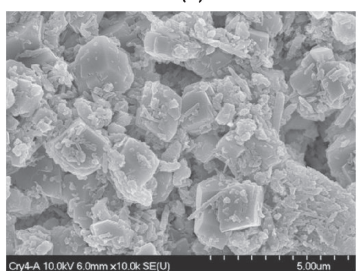

(c)

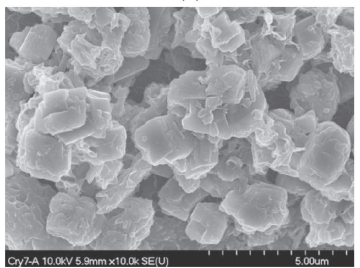

(d)

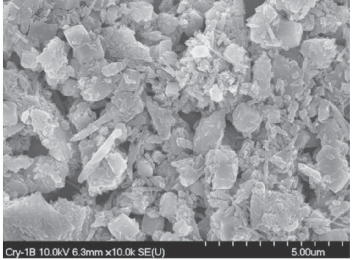

$(\mathrm{a}-1)$

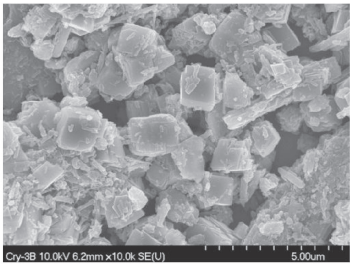

(b-1)

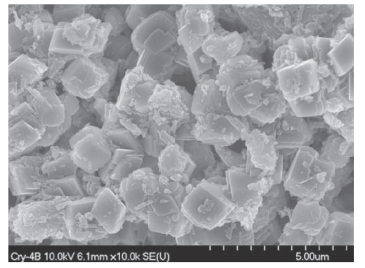

(c-1)

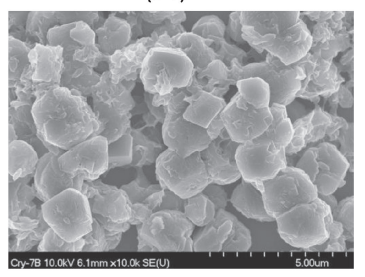

$(d-1)$
Fig. 3 SEM image of carbonation products after reaction at various temperatures in distilled water and alkali solution: $80^{\circ} \mathrm{C}$ (a) $(\mathrm{a}-1), 100^{\circ} \mathrm{C}$ (b) $(\mathrm{b}-1), 140^{\circ} \mathrm{C}(\mathrm{c})(\mathrm{c}-1), 260^{\circ} \mathrm{C}(\mathrm{d})(\mathrm{d}-1)$.

\subsection{Methods}

The starting material for the carbonation was the heattreated chrysotile. The activated chrysotile was crushed in a jet mill into grains that would pass through a 200 mesh sieve. The grain size was measured by a particle size analyzer (KMC-1B, KME Co.). The chemical composition of chrysotile was measured by ICP-AES (JY 38 Plus, France Jobin Yvon).

All carbonation experiments were performed in a $1 \mathrm{~L}$ coldseal type stainless steel vessel. Unless otherwise specified, the following experimental conditions were maintained: the $\mathrm{CO}_{2}$ partial pressure was $3 \mathrm{MPa}$, reaction time was $1 \mathrm{~h}$, and reaction temperature was varied from 80 to $260^{\circ} \mathrm{C}$. The reaction was carried in distilled water and in alkali solution. The $\mathrm{pH}$ of the alkali solution was controlled by adding $1 \mathrm{M} \mathrm{NaOH}$ solution (OCI, extra pure). The mineral/water/liquid $\mathrm{CO}_{2}$ mixture was continuously agitated to prevent settling of the solids.

After carbonation, the reaction products were collected and analyzed by XRD (X'pert MPD X-ray diffractometer with graphite monochromatized $\mathrm{CuK} \alpha$ radiation, Phillips Co.). The microstructure of the synthesized products was examined using a transmission electron microscope (TEM, JEM 2200FS, JEOL) coupled with an energy dispersive X-ray spectrometer (EDS, Oxford) and a scanning electron microscope (FE-SEM, S-4700, Hitachi). TEM samples were dispersed in distilled water using an ultrasonic probe. They were air dried after being placed onto a holey carbon $\mathrm{Cu}$ grid. SEM examination was carried out at a working voltage of 
$15 \mathrm{keV}$. Sample powder was sedimented on a $\mathrm{Cu}$ microgrid and coated with osmium tetraoxide $\left(\mathrm{OsO}_{4}\right)$.

The carbonation rate of chrysotile to magnesite was calculated by thermo-gravimetric analysis (TG-DTA) at atmospheric pressure (DTG-60H, Shimazu). Profiles were obtained for a temperature range of $30-900^{\circ} \mathrm{C}$ with a constant heating rate of $10^{\circ} \mathrm{C} / \mathrm{min}$ under argon.

\section{Results and Discussion}

The X-ray diffraction patterns of carbonated samples at temperatures of 80,140 and $260^{\circ} \mathrm{C}$ are shown in Fig. 1. XRD patterns of carbonation samples from different $\mathrm{pH}$ at weak acidic and alkali condition were almost identical. Therefore, only patterns from alkali solutions are presented here. The reaction time was $1 \mathrm{~h}$ and the $\mathrm{pH}$ was 6-7 for weak acidic and $\mathrm{pH} 13$ for alkali solutions, respectively. After the carbonation reaction at $80^{\circ} \mathrm{C}$, rather poorly crystallized magnesite appeared suggesting that the reaction was not pronounced. At this condition, very small amount of chrysotile was recrystallized and a peak at low angle is suggested by the formation of saponite $\left[\mathrm{M}_{x / n}{ }^{n+}\left(\mathrm{Mg}_{6}\right)\left(\mathrm{Si}_{8-x} \mathrm{Al}_{x}\right) \mathrm{O}_{20}(\mathrm{OH})_{4}\right.$. $n \mathrm{H}_{2} \mathrm{O}$ ] based on the octahedral $\mathrm{Mg}$ layers was also noticed (Fig. 1(c)). At $140^{\circ} \mathrm{C}$, the synthesis of highly crystalline magnesite was evident after the carbonation (Fig. 1(d)). At $260^{\circ} \mathrm{C}$, saponite became more stable at the expense of transformed mangesite (Fig. 1(e)).

The surface morphology of the synthesized magnesite samples carbonated in weak acidic and alkali solution was examined by SEM (Fig. 3). The micrographs appears to suggest that the carbonation products reacted more in alkali solutions than in distilled water at all temperatures in view of the morphological changes. Thus, after the reaction at $80^{\circ} \mathrm{C}$ in distilled water, magnesite crystals are hardly observed suggesting that the starting materials were not reacted with $\mathrm{CO}_{2}$ (Fig. 3(a)). In contrast, after the reaction at $80^{\circ} \mathrm{C}$ in alkali solution, few magnesite crystals finer than $1 \mu \mathrm{m}$ with a more regular morphology were observed, which is typical for the carbonate particles. Here, the unreacted chrysotile crystals exhibited partially lath-type morphology; most of them were agglomerated to irregular shapes (Fig. 3(a-1)) after the reaction thus maintaining the chemical composition of chrysotile.

After the reaction at $100^{\circ} \mathrm{C}$ in distilled water, the aggregation of chrysotile crystals with irregular edges/ corners under $10 \mu \mathrm{m}$ was formed by partial dissolution and the crystal face of magnesite was poorly developed. The size of magnesite was about $1.5 \mu \mathrm{m}$ (Fig. 3(b)). On the contrary, at $100^{\circ} \mathrm{C}$ in alkali solution, the crystal faces of magnesite were observed well-developed and some chrysotile crystals were still seen to remain unreacted (Fig. 3(b-1)).

After carbonation at $140^{\circ} \mathrm{C}$ in both solutions, well-faceted rhombohedral magnesite crystals appeared and the size of the magnesite crystals was about $2-3 \mu \mathrm{m}$. However, the unreacted chrysotile crystals were more after the reaction in distilled water than that in alkali solution (Fig. 3(c), (c-1)). This observation suggests that carbonation rate in the alkali solution was much higher. After increasing the reaction temperature to $260^{\circ} \mathrm{C}$, most of the edges and corners of the carbonates were eroded by the partial dissolution. On the surface of magnesite crystals, the cavity and so called 'curled habits' were also

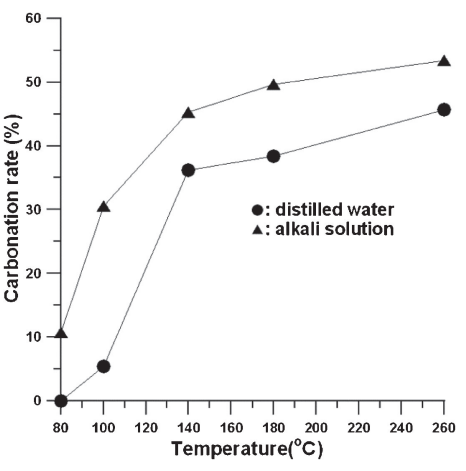

Fig. 4 The carbonation rate of chrysotile at various reaction temperatures, reaction time $1 \mathrm{~h}, \mathrm{CO}_{2}$ partial pressure $3 \mathrm{MPa}, \mathrm{pH}$ 6-7 and $\mathrm{pH} 13$.

observed and their chemical composition was found to be comparable to that of saponite (Fig. 3(d), (d-1)).

So far, it has been demonstrated that the fibrous shape of chrysotile was transformed to rhombohedra or agglomerates of chrysotile with the partial leaching of $\mathrm{Mg}^{2+}$ during the carbonation reaction. Here, the morphological modification of chrysotile during the transformation is worthy of further study in relation to the possible reduction of its toxicity.

The extent of the carbonation was determined by calcining the final product using TGA, since the weight change during calcination corresponds to the amount of $\mathrm{CO}_{2}$ captured by carbonation (Fig. 4). The result shows that the carbonation reaction of heated chrysotile was significantly higher in more alkali solution $(\mathrm{pH} \mathrm{13)}$ than in distilled water. The carbonation rate was found to be approximately 0 and $11 \%$ at $80^{\circ} \mathrm{C}$, 5 and $31 \%$ at $100^{\circ} \mathrm{C}, 38$ and $50 \%$ at $180^{\circ} \mathrm{C}$, and 45 and $53 \%$ at $260^{\circ} \mathrm{C}$ in distilled water and alkali solution, respectively. TGA result suggests that the amount of transformed magnesite increases very rapidly up to $140^{\circ} \mathrm{C}$. Afterwards, it increases at a much slower rate up to $260^{\circ} \mathrm{C}$. O'Connor et al. $(2005)^{16)}$ reported that the maximum carbonation rate was $57 \%$ at $155^{\circ} \mathrm{C}$ and $12 \mathrm{MPa}$. The carbonation rate in this study obtained at $260^{\circ} \mathrm{C}$ under $\mathrm{CO}_{2}$ partial pressure of $3 \mathrm{MPa}$ in the alkali solution is comparable to the results of O'Connor et al. The initial stage of Mg-silicate dissolution is always nonstoichiometric with preferential $\mathrm{Mg}$ release at $\mathrm{pH} \leq 8$, but preferential Si release occurs at $\mathrm{pH} \geq 10 .{ }^{17)}$ At high $\mathrm{pH}$, where Si surface sites are deprotonated and therefore carry negative charge, detachment of silicon appears to control the overall silicate dissolution rates. ${ }^{18)} \mathrm{Si}$ is preferentially released from the chrysotile surface in an alkali solution consistent with its surface structure: isolated $\mathrm{SiO}_{4}$ tetrahedra can be easily removed from the surface, leaving $\mathrm{Mg}$ octahedra branched together via $\mathrm{Mg}-\mathrm{O}-\mathrm{Mg}$ bonds, as in brucite or $\mathrm{Mg}$ bearing sheet silicate. ${ }^{19)}$ The formation of the Mg-rich layer on the meta-chrysotile surface can be described as:

$$
\begin{aligned}
& \left.>\mathrm{Mg}_{3} \mathrm{Si}_{2} \mathrm{O}_{7} \text { (surface }\right)+7 \mathrm{H}_{2} \mathrm{O} \\
& \quad \rightarrow \mathrm{Mg}_{3}(\mathrm{OH})_{6}(\text { surface })+2 \mathrm{H}_{4} \mathrm{SiO}_{4}(\mathrm{aq}) .
\end{aligned}
$$

The dissolution of the $\mathrm{Mg}$-rich layer requires the breaking of $\mathrm{Mg}-\mathrm{O}-\mathrm{Mg}$ bonds, which is promoted by the hydration of metachrysotile surface with the formation of $>\mathrm{MgOH}_{2}{ }^{+}$ species, as is the case of oxides or carbonates.

The $\mathrm{pH}$ determines which steps dominate the reaction sequence and, accordingly, the proportions of the carbonic 


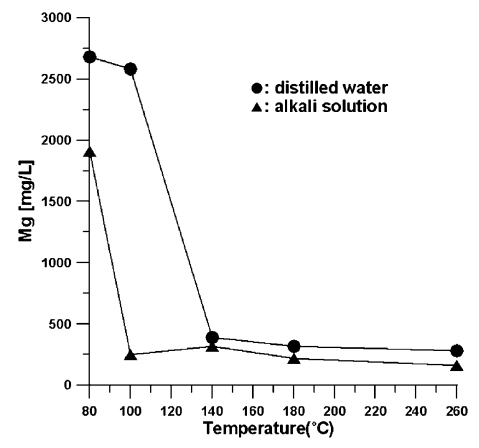

Fig. $5 \mathrm{Mg}$ residue after mineral carbonation at various temperature, reaction time $1 \mathrm{~h}, \mathrm{CO}_{2}$ partial pressure $3 \mathrm{MPa}, \mathrm{pH}$ 6-7 and $\mathrm{pH} 13$.

species. ${ }^{20)}$ At low $\mathrm{pH}(\sim 4)$, the production of $\mathrm{H}_{2} \mathrm{CO}_{3}$ dominates; in the middle of the $\mathrm{pH}$ range $(\sim 6), \mathrm{HCO}_{3}{ }^{-}$ production dominates; and at a high $\mathrm{pH}(\sim 9), \mathrm{CO}_{3}{ }^{2-}$ production dominates. ${ }^{21)}$

In turn, the magnesium hydroxide can be carbonated according to

$$
>\mathrm{MgOH}_{2}{ }^{+}+\mathrm{CO}_{3}^{2-}=\mathrm{MgCO}_{3}{ }^{-}+\mathrm{H}_{2} \mathrm{O} \text {. }
$$

The amounts of $\mathrm{Mg}^{2+}$ residue in the solution after the carbonation reaction at various reaction temperatures in distilled water and in alkali solution are presented in Fig. 5. After carbonation up to $100^{\circ} \mathrm{C} \mathrm{Mg}^{2+}$ residue in distilled water is almost an order higher than that in alkali solution. However, it decreased sharply after carbonation at $140^{\circ} \mathrm{C}$. In contrast, residual $\mathrm{Mg}^{2+}$ in alkali solution dropped rapidly at $100^{\circ} \mathrm{C}$.

Regarding the carbonation, it was generally accepted that the mineral dissolution in aqueous phase can be increased by the presence of anions, protons, organic ligands, and weak acids. Park et al. (2004) ${ }^{22)}$ examined various solvents to enhance the dissolution of magnesium, and suggested that a $\mathrm{pH}$ swing is needed to achieve a higher overall conversion for the $\mathrm{CO}_{2}$ aqueous sequestration process. Similarly, in this study, the high amount of $\mathrm{Mg}^{2+}$ dissolved in weak acid (distilled water) remained unreacted during the carbonation at $100^{\circ} \mathrm{C}$. In contrast, in alkali solution, the reaction of dissoloved was almost completed at $100^{\circ} \mathrm{C}$ as shown in Fig. 5. However, in weak acid, significantly conversion of residual $\mathrm{Mg}^{2+}$ for mineral carbonation was possible only after the reaction temperature was increased to $140^{\circ} \mathrm{C}$ suggestive of the higher energy consumption. These results suggest that the direct carbonation method in alkali solution is of great significance in spite of the lower $\mathrm{Mg}^{2+}$ dissolution rate. Therefore, the carbonation reaction in alkali solution is considered to be economically more viable than the neutral and acid conditions when one considers the cost for the higher energy operation and $\mathrm{pH}$ swing process.

\section{Conclusion}

The carbonation of heated chrysotile was studied to examine the feasibility of converting carbon dioxide to a thermally stable form of magnesite in both alkali and weak acid solutions. The conversion rate of chrysotile to magnesite in the alkali solution was higher than that in the distilled water. The carbonation rate was found to be 5 and $31 \%$ at $100^{\circ} \mathrm{C}$ and 45 and $53 \%$ at $260^{\circ} \mathrm{C}$ in distilled water and alkali solution, respectively. The amount of $\mathrm{Mg}^{2+}$ residue in reaction solution after carbonation up to $100^{\circ} \mathrm{C}$ was much higher in distilled water than in alkali solution. Therefore, a $\mathrm{pH}$ swing and high energy should be provided to achieve a higher overall conversion in distilled water. On the contrary, the suggested direct method in alkali solution has an advantage over the conventional method since it can be operated at lower temperature without the $\mathrm{pH}$ swing process.

In addition, the morphological change of chrysotile during the carbonation is of another significance in view of the reduction of chrysotile's toxicity. Fibrous chrysotile transformed to agglomerate at $80^{\circ} \mathrm{C}$ in alkali solution, and to wellfaceted rhombohedral magnesite crystals at $140^{\circ} \mathrm{C}$ in both solutions. The morphogical alteration is expected to convert chrysotile asbestos into a non-hazardous material.

\section{Acknowledgements}

This work was supported by the "Utilization and Sequestration of $\mathrm{CO}_{2}$ by Using Industrial Minerals" program, KIGAM. We also wish to thank the KBSI Jeonju Center for the electron microscope analysis.

\section{REFERENCES}

1) K. Anastasiadou, D. Axiotis and E. Gladarakos: J. Hazard. Mater. 179 (2010) 926-932.

2) L. A. Heasman and G. Baldwin: Waste Manag. Res. 4 (1986) 215.

3) A. Gualtieri: J. Appl. Polym. Sci. 75 (2000) 713-720.

4) M. Gulumian: J. Toxicol. Environ. Health Part B 8 (2005) 453-483.

5) M. Klockars, M. Hedenborg and E. Vanhala: Arch. Environ. Health 45 (1990) 8-14.

6) C. J. Martin: Miner. Mag. 41 (1977) 453-459.

7) T. Zaremba and M. Peszko: J. Therm. Anal. Calorim. 92 (2008) 873877.

8) C. Leonelli, P. Veronesi, D. N. Boccaccini, M. R. Rivasi, L. Barbieri, F. Andreola, I. Lancellotti, D. Rabitti and G. C. Pellacani: J. Hazard. Mater. B 135 (2006) 149-155.

9) D. N. Boccaccini, C. Leonelli, M. R. Rivasi, M. Romagnoli, P. Veronesi, G. C. Pellacani and A. R. Boccaccini: J. Eur. Soc. 27 (2007) 1855-1858.

10) P. Plescia, D. Gizzi, S. Benedetti, L. Camilucci, C. Fanizza, P. Simone and F. Paglietti: Waste Manag. 23 (2003) 209-218.

11) W. K. O'Connor, D. C. Dahlin, G. E. Rush, S. J. Gerdemann, L. R. Penner and D. N. Nilsen: The report of the US Department of Energy, DOE/ARC-TR-04-002 (2004).

12) P. S. Whitfield and L. D. Mitchell: Appl. Geochem. 24 (2009) 16351639.

13) D. Daval, I. Matinez, J. Corvisier, N. Findling, B. Goffé and F. Guyot: Chem. Geol. 265 (2009) 63-78.

14) L. Bonneau, H. Suquet, C. Malard and H. Pezeart: Environ. Res. 41 (1986) 251-267.

15) W. Li, W. Li, B. Li and Z. Bai: Chem. Eng. Res. Des. 87 (2009) 210-215.

16) W. K. O’Connor, D. C. Dahlin, G. E. Rush, S. J. Gerdemann, L. R. Penner and D. N. Nilson: The report of the US Department of Energy, DOE/ARC-TR-04-002 (2005).

17) R. C. Bales and J. J. Morgan: Geochim. Cosmochim. Acta 49 (1985) 2281-2288.

18) P. V. Brady and J. V. Walther: Geochim. Cosmochim. Acta 53 (1989) 2823-2830.

19) O. S. Pokrovsky and J. Schott: Geochim. Cosmochim. Acta 64 (2000) 3313-3325.

20) Y. K. Kharaka, L. Y. Leong, C. G. Doran and G. N. Breit: Proc. 5th Int. Petrol Environment Conference, (1998) pp. 281-282.

21) A. Berg and S. A. Banwart: Chem. Geol. 163 (2000) 25-42.

22) A. H. Park, R. Jadhav and L. S. Fan: Can. J. Chem. Eng. 59 (2004) 5241-5247. 